\title{
Application of Failure Mode Effect and Criticality Analysis (FMECA) to a Computer Integrated Manufacturing (CIM) Conveyor Belt
}

\author{
Isam A.Q. Elbadawi \\ Industrial Engineering Department \\ University of Hail \\ Hail, Saudi Arabia \\ i.elbadawi@uoh.edu.sa \\ Imran Ali Chaudhry \\ Industrial Engineering Department \\ University of Hail \\ Hail, Saudi Arabia \\ i.chaudhry@uoh.edu.sa
}

\author{
Mohamed Arafat Ashmawy \\ Mechanical Engineering Department \\ University of Hail, Saudi Arabia and \\ Suez University, Suez, Egypt \\ arafat_696@yahoo.com \\ Naim Ben Ali \\ Industrial Engineering Department \\ University of Hail \\ Hail, Saudi Arabia \\ naimgi2@yahoo.fr
}

\author{
Wan Ahmad Yusmawiza \\ Industrial Engineering Department \\ University of Hail \\ Hail, Saudi Arabia \\ yusmawiza@iium.edu.my \\ Ayyaz Ahmad \\ Industrial Engineering Department \\ University of Hail \\ Hail, Saudi Arabia \\ ay.ahmad@uoh.edu.sa
}

\begin{abstract}
Fault finding and failure predicting techniques in manufacturing and production systems often involve forecasting failures, their effects, and occurrences. The majority of these techniques predict failures that may appear during the regular system production time. However, they do not estimate the failure modes and they require extensive source code instrumentation. In this study, we suggest an approach for predicting failure occurrences and modes during system production time intervals at the University of Hail ( $\mathrm{UoH})$. The aim of this project is to implement failure mode effect and criticality analysis (FMECA) on computer integrated manufacturing (CIM) conveyors to determine the effect of various failures on the CIM conveyor belt by ranking and prioritizing each failure according to its risk priority number (RPN). We incorporated the results of FMECA in the development of formal specifications of fail-safe CIM conveyor belt systems. The results show that the highest RPN values are for motor over current failure (450), conveyor chase of vibration (400), belt run off at the head pulley (200), accumulated dirt (180), and Bowed belt (150). The study concludes that performing FMECA is highly effective in improving CIM conveyor belt reliability and safety in the mechanical engineering workshop at UoH.
\end{abstract}

Keywords-reliability; failure mode effect criticality analysis; maintenance

\section{INTRODUCTION}

Anticipating potential failure occurrences during conveyor productive time is important to achieve system pliability and to overcome unexpected and dangerous failure consequences. As machining tool systems become increasingly more complicated, the further development of system scale and functions, increases the probability of system failure. This paper starts with a brief historical overview of FMECA and the current international standards followed by a discussion of the core concept and implementation procedures of FMECA. Finally, the paper illustrates the application of FMECA on the CIM conveyor in the mechanical engineering workshop at UoH. A significant number of studies on the reliability and the related risks of manufacturing plants have been conducted. Consequently policies for risk management, maintenance policies, and suggestions for improving the production process have been developed. A number of these studies aimed at minimizing the downtime rate and improving the equipment's availability and reliability. Furthermore, in order to improve the system efficiency with an optimized resource amount and to minimize the probability of system failure, several maintenance strategies were implemented, various approaches and maintenance planning models were developed, and many technical manufacturing specifications were listed. However, a comprehensive approach which tackles the potential causes and effects is yet to be developed [1].

\section{FAILURE MODE EFFECT ANALYSIS (FMEA)}

\section{A. FMEA}

Every machine or system used in the manufacturing industry might fail to work properly. The failure may be caused by machines, materials, measurements, manpower, methods, and/or environmental factors. Failure prediction methods have been used by leading production and manufacturing firms to control and minimize the impacts of failures on the cost of the product defect and the operational risk of manufacturing processes. A significant number of industrial firms and research organizations dedicated considerable efforts to analyze failure modes and their effects on manufacturing and 
production systems. An important model was developed by the National Aeronautics and Space Administration (NASA) in which they used a number of reliability practices in several space programs such as Viking, Galileo, Apollo, and Voyager to analyze the failure mode behavior of their systems [2]. According to NASA, FMEA is a proactive quality tool for evaluating potential failure modes and their causes. FMEA helps in prioritizing the failure modes, recommending corrective measures for the avoidance of catastrophic failures and, therefore, improving the quality of the manufacturing and production processes. The objectives of FMEA include understanding the criticalities and dependencies of all types of systems as well as facilitating the evaluation of process manipulation options to achieve high level of system reliability.

\section{B. Failure Modes Effects and Criticality Analysis (FMECA)}

FMECA methodology is an advanced level of FMEA designed to assess the risk associated with all failure modes. The objective of FMECA is to design maintenance procedures required to eliminate points of failures as well as any catastrophic or critical consequence of such failures. The fundamental purpose is to initiate actions that reduce the likelihood of failure in the process. In 1965, the American aerospace manufacturer, Grumman, developed FMECA to identify the potential failures of the manipulation system of the flight vehicles powered by jet engine. The severity (S), occurrence (O) and detectability (D) of the failure effect can be analyzed and quantified to evaluate the risk associated with the potential problems identified through the analysis.

- Severity. A value of 1 stands for an extremely low severity while a value of 10 stands for an extremely high severity as shown in Table I.

- Occurrence is related to number of the preventive actions taken for the respective potential failure causes. The assessment of the probability for the occurrence of a potential failure cause is carried out while considering all listed preventive actions. A value of 10 is assigned, if it is likely that the potential failure cause will occur. A value of 1 is assigned for a very improbable potential failure cause. Thus, the $\mathrm{O}$ assessment makes a statement concerning the quantity of defective components remaining in an entire batch of a certain product [3] (see Table I).

- Detection is correlated to the actions taken to detect the respective potential failure causes. A value of 10 is assigned if no detection actions are mentioned whatsoever. A value of 1 is assigned, if the probability for the detection of the failure before the delivery to the customer is very high. Thus, the $\mathrm{D}$ assessment makes a statement concerning the quantity of undetected, defect components in an entire batch of a certain product as shown in Table I.

In FMECA, risk is assessed with a value called risk priority number (RPN). RPN value is the quantitative measure in FMECA and is used to compare, analyze, and prioritize failures. These are important in order to suggest proper solutions and corrective maintenance procedures. RPN is calculated by multiplying Severity, Occurrence, and Detectability as shown in (1).

$$
R P N=S \times O \times D
$$

As shown in Table I, the highest RPN value is 1000 which indicates the most dangerous failure and the lowest RPN value is 1 which indicates an unnoticeable failure, a failure that would be solved before the customer notices.

TABLE I. RPN SCALE

\begin{tabular}{|c|c|c|c|c|c|c|}
\hline & $\begin{array}{l}\text { How Severe } \\
\text { would the } \\
\text { impact be? }\end{array}$ & \multicolumn{2}{|c|}{$\begin{array}{c}\text { How likely is it to } \\
\text { happen? }\end{array}$} & $\begin{array}{l}\text { How detectable } \\
\text { is the problem? }\end{array}$ & \multicolumn{2}{|c|}{$\begin{array}{l}\text { What is the } \\
\text { RPN? }\end{array}$} \\
\hline 莺 & $\begin{array}{l}\text { Reduce the } \\
\text { severity of } \\
\text { failure effects }\end{array}$ & \multicolumn{2}{|c|}{$\begin{array}{c}\text { Reduce the failure } \\
\text { rate }\end{array}$} & $\begin{array}{l}\text { Increase the } \\
\text { detection rate of } \\
\text { failure during the } \\
\text { failure process }\end{array}$ & & \\
\hline & $\begin{array}{c}\text { Severity Risk } \\
\text { (S) }\end{array}$ & \multicolumn{2}{|c|}{$\begin{array}{c}\text { Occurrence } \\
\text { (O) }\end{array}$} & $\begin{array}{l}\text { Detectability } \\
\text { (D) }\end{array}$ & \multicolumn{2}{|c|}{$\mathbf{R P N}=\mathbf{S} \times \mathbf{O} \times \mathbf{D}$} \\
\hline 10 & $\begin{array}{c}\text { Serious safety } \\
\text { hazards without } \\
\text { warning }\end{array}$ & $\begin{array}{l}\text { More } \\
\text { than } 1 \text { in } \\
2\end{array}$ & $\begin{array}{c}\text { Very } \\
\text { High: } \\
\text { failure } \\
\text { evitable }\end{array}$ & $\begin{array}{c}\text { Absolute } \\
\text { uncertainty: } \\
\text { cannot detect the } \\
\text { problem }\end{array}$ & 1000 & $\mid \begin{array}{c}\text { Most } \\
\text { dangerous }\end{array}$ \\
\hline 9 & $\begin{array}{l}\text { Hazard with } \\
\text { warning }\end{array}$ & 1 in 3 & $\begin{array}{l}\text { Very } \\
\text { high }\end{array}$ & Very remote & 729 & \\
\hline 8 & Very high & 1 in 8 & High & Remote & 512 & \\
\hline 7 & High & 1 in 20 & High & Very low & 343 & \\
\hline 6 & Moderate & 1 in 80 & Moderate & Low & 216 & \\
\hline 5 & Low & 1 in 400 & Moderate & Moderate & \begin{tabular}{|l|}
125 \\
\end{tabular} & \\
\hline 4 & Very low & $\begin{array}{c}1 \text { in } \\
2000\end{array}$ & Moderate & Highly moderate & 64 & \\
\hline 3 & Minor & $\begin{array}{c}1 \text { in } \\
15000\end{array}$ & Low & High & 27 & \\
\hline 2 & Very minor & $\begin{array}{c}1 \text { in } \\
150000\end{array}$ & Low & Very high & 8 & \\
\hline 1 & $\begin{array}{c}\text { None- No } \\
\text { effect: } \\
\text { customer might } \\
\text { not notice it }\end{array}$ & 1500000 & $\begin{array}{l}\text { Remote: } \\
\text { Rare } \\
\text { event, no } \\
\text { data of } \\
\text { such } \\
\text { failure in } \\
\text { the past }\end{array}$ & $\begin{array}{l}\text { Almost Certain: } \\
\text { (Automation), } \\
\text { current system } \\
\text { certainly detects } \\
\text { the failure }\end{array}$ & 1 & \begin{tabular}{|c|} 
No one \\
would \\
notice: \\
failure \\
would be \\
solved \\
before the \\
customer \\
notices
\end{tabular} \\
\hline
\end{tabular}

\section{FMECA Standards}

There is a number of published guidelines and standards for the requirements and recommended reporting format of FMEAs and FMECAs [4]. Some of the main published standards for this type of analysis include SAE J1739and MILSTD-1629A. In addition, many industries and companies have developed their own procedures to meet the specific requirements of their products or processes [5].

- MIL-STD 1629 - Procedures for performing failure mode and effect analysis.

- IEC 60812 - Procedures for failure mode and effect analysis (FMEA).

- BS 5760-5 - Guide to failure modes, effects and criticality analysis (FMEA and FMECA). 
- SAE ARP 5580 - Recommended failure modes and effects analysis (FMEA) practices for non-automobile applications [6].

- SAE J1739 - Potential Failure Mode and Effects Analysis in design (Design FMEA) and potential failure mode and effects analysis in manufacturing and assembly processes (Process FMEA) and effects analysis for machinery (Machinery FMEA) [7].

\section{Benefits of FMECA}

FMECA allows:

- High degree of complexity.

- Uniform quantification of risk.

- Results to be correlated directly with actual risks.

- Easy modeling of the effect of various methods of mitigation/detection on risk.

- Implementation of a well-documented record of improvements from corrective actions.

- Acquiring information useful in developing test programs and in-line monitoring criteria.

- Obtaining historical information useful in analyzing potential product failures during the manufacturing process.

- Obtaining new ideas for improvements in similar designs or processes.

E. Types of FMECA

FMECA can be classified into three main types as shown in Figure 1.

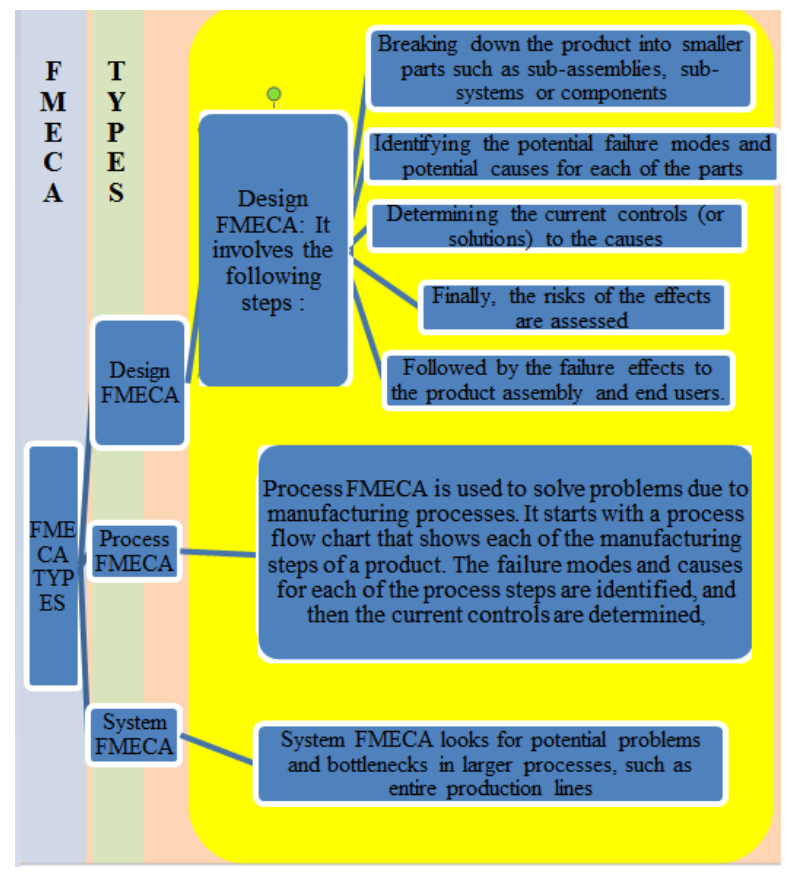

Fig. 1. FMECA types

\section{STUDY OBJECTIVES}

This study employed FMECA techniques to minimize the failure mode of the CIM conveyor in the mechanical engineering workshop at the UoH. The study aims at providing CIM users with a general background about the techniques available for failure effects analysis and their maintainability analysis, reliability prediction and safety analysis. This paper proposes a risk based maintenance method, which relies on regular and automatic update of risk analyses of the equipment including the equipment failure history. The method provides up-to-date information about the equipment's risks.

\section{PREVIOUS WORK}

Authors in [8], presented risk in early design phase (RED) as a new method to introduce information about dysfunction during design phase of functionalities based on the following points:

- The storage of breakdown events, (system breakdown database)

- Matrix linking parts and functions, (system components function and relationship)

- Translation of parts breakdown into risks of functional failure and database update. Risk pooling of system breakdown and system components failure.

Later, they added an inspection module to improve maintenance operations schedule and to minimize failure risk by developing an optimal inspection strategy. They also pointed out the impact of the risk formalism on the assessment of occurrence, consequences and then the judgment of risk level. These results highlight the need for improving the quality of risk analyses.

In [9], authors made a synthesis of 25 risk based maintenance (RBM) methods, presented their steps and described their main drawbacks. In particular they presented Khan and Haddara's RBM process. They provided detailed description of each step as well as the factors affecting the quality of risk analysis evaluations. Three major factors and their related contributors were highlighted. Authors in [10] used the FMEA method to study the reliability of a wind turbine (WT) system, using a proprietary software reliability analysis tool. They compared the quantitative results of an FMEA and reliability field data from real wind turbine systems and their assemblies. Their results may be useful for future WT designs. Authors in [11] argue that a proper use of process Failure Modes and Effects Analysis (PFMEA) could be of a great importance for the automotive industry. Authors in [12] described the application of FMECA in Toshiba bulb factory in Monfiya, Egypt. They found that FMECA is an efficient technique for reducing the chances of catastrophic failures. The application of FMECA also helped to increase the reliability and availability of the machines in the factory. Authors in [13] devised an effective tool for solving the problems related to the quality of the manufacturing process through the application of FMECA. They identified and eliminated the problems they encountered during the manufacturing process of a cylinder head in an internal 
combustion engine. However, the value of introducing FMECA to evaluate the reliability and to improve the maintenance process of the CIM conveyor belt in an academic setting is still under-researched. Thus, this study fills an important gap in this field.

\section{RESEARCH METHODOLOGY}

\section{A. Conveyor Belt}

The conveyor system is part of the learning production system used in the workshops of the Mechanical Engineering department at the University of Hail. The conveyor consists of a feed belt and a rotary table. When students practice hands-on processing, the feed belt transports objects placed on its left end from the CIM robot to the right side of the assembly station. The belt has a bar code reader and photo-electric cells, which signal when an object arrives at its ends. Controlling the motion of conveyor belt is synchronized with a CIM robot and may be switched on and off: it has to be ON while waiting for a new object and has to be switched OFF when an object is at the end of the belt. The conveyor belt is used as a means to transport material from one station to another. A description of the conveyor belt is illustrated in Figure 2, and a brief of list of the specifications is provided in Table II. The conveyor belt either runs empty (while waiting for an object to be placed on it) or transports an object.

TABLE II. CONVEYOR BELT SPECIFICATIONS

\begin{tabular}{|c|c|c|}
\hline Parameter & Value & Unit \\
\hline Motor drive & 2.5 & $\mathrm{HP}$ \\
\hline Belt width & 40 & $\mathrm{~cm}$ \\
\hline Assembly line length & 6.4 & $\mathrm{~m}$ \\
\hline Belt speed & 29 & $\mathrm{~cm} / \mathrm{s}$ \\
\hline Assembly line height & 87 & $\mathrm{~cm}$ \\
\hline Control pad height & 130 & $\mathrm{~cm}$ \\
\hline Distance between each work station & 1.5 & $\mathrm{~m}$ \\
\hline
\end{tabular}

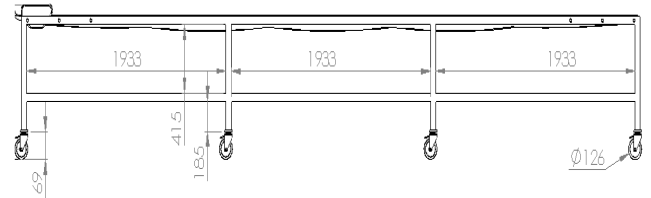

Fig. 2. Conveyor belt diagram and dimensions

\section{B. Utilizing FMECA}

The methodology of this study utilizes FMECA according to the following sequence: FMECA scope, FMECA analysis, FMECA ranking, FMECA RPN calculations, FMECA verification, FMECA report . A detailed framework is illustrated in Figure 3. Data were collected and organized in a fishbone diagram as shown in Figure 4. The failure modes and their causes were identified for the conveyor belt. The three key indices (Severity, Occurrence and Detection) we reassessed and their analysis was carried out with the help of FMECA Worksheet. Finally, the necessary corrective actions were recommended.

\section{Ishakawa Fishbone Analysis}

The CIM conveyor belt was monitored for a total of 45 hours ( 3 hours a week over the period of 15 weeks). 100 failures were detected and categorized through Ishakawa fishbone analysis. The study found that the material type and property have the highest effect on the conveyor belt failures, while the method has the lowest. We investigated the list of conveyor belt failures in the Ishakawa fishbone and categorized them into a technical classification list as shown in Figure 5. We found that $45 \%$ of failures were caused by the belt of the conveyor and 2 percent by the robot alignments as shown in Figure 5 .

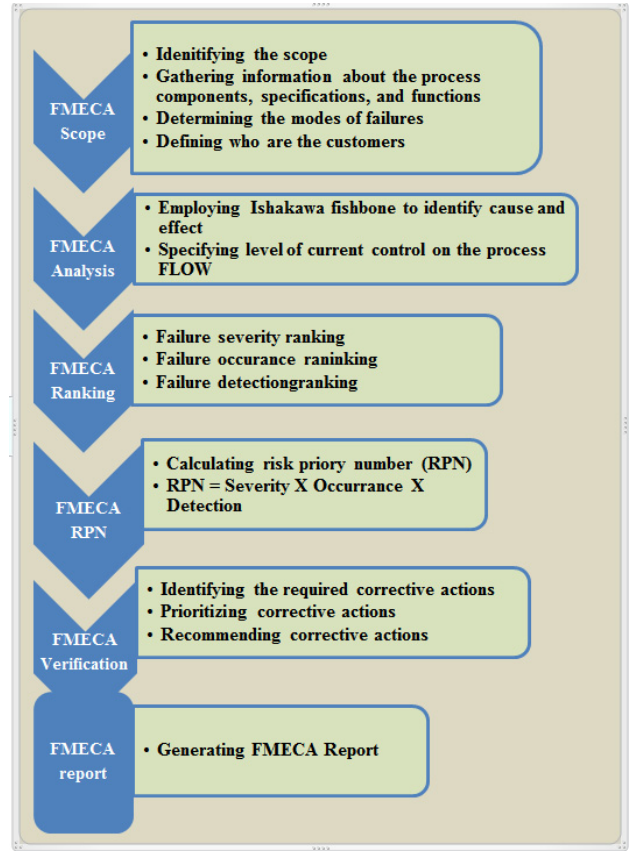

Fig. 3. FMECA framework

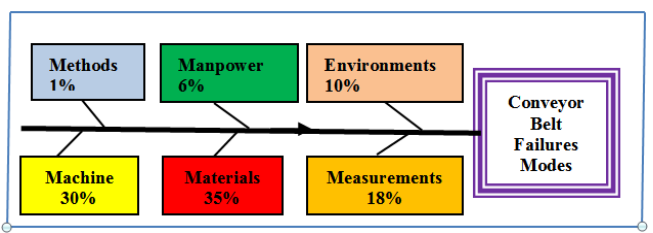

Fig. 4. Conveyor belt failures Ishakawa fishbone

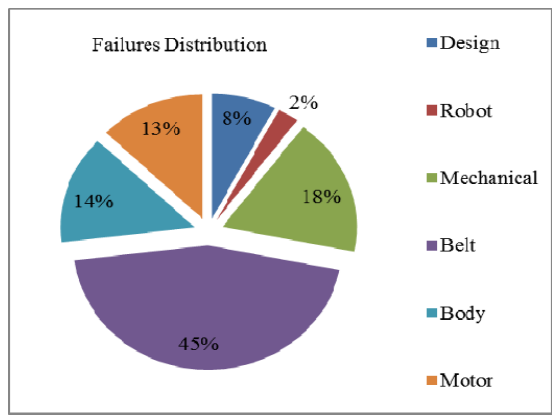

Fig. 5. Failures distribution. 


\section{Risk Priority Number (RPN)}

The failure modes and their causes were identified for each of the three key indices (Severity, Occurrence and Detection). We investigated 150 failures of the conveyor, and then categorized them into two groups:

\section{1) Belt failures}

The results summarized in FMECA Worksheet in Table III revealed that the RPN was the highest $(R P N=200)$ for belt runs off at the head pulley, mainly owing to the degree of severity of the failure in disrupting the entire conveyor belt motion. Hence, extra attention should be given to the corrective measures for the belt runs off at the head pulley to eliminate the failure. The next priority should be given to the bowed belt $(\mathrm{RPN}=150)$, mainly because of its criticality affecting belt efficiency. For the excessive belt stretch $(\mathrm{RPN}=64)$ and belt slip $(\mathrm{RPN}=30)$ their effect is less than the previous two failures, but found to be the correlated to the head pulley alignments.

\section{2) Motor failures}

From Table IV it can be seen that the severity and occurrence of the motor over current and motor vibration are very high. The data revealed that both failures are critically affecting the CIM conveyor belt efficiency. Figure 6 shows that the motor over current RPN is 450 and it is the highest value, and the motor vibration RPN is 400 .

TABLE III. RPN CONVEYOR BELT RESULTS

\begin{tabular}{|c|c|c|c|c|}
\hline Failure Mode & $\begin{array}{c}\text { S } \\
(\mathbf{1 - 1 0})\end{array}$ & $\begin{array}{c}\text { O } \\
(\mathbf{1 - 1 0})\end{array}$ & $\begin{array}{c}\text { D } \\
(\mathbf{1 - 1 0})\end{array}$ & RPN \\
\hline Belt slip & 10 & 1 & 3 & 30 \\
\hline Belt runs off at the head pulley & 10 & 4 & 5 & 200 \\
\hline Excessive belt stretch & 8 & 4 & 2 & 64 \\
\hline Bowed belt & 6 & 5 & 5 & 150 \\
\hline
\end{tabular}

TABLE IV. RPN MOTOR FAILURE RESULTS

\begin{tabular}{|c|c|c|c|c|}
\hline \multirow{2}{*}{ Motor Failures } & S & O & D & \multirow{2}{*}{ RPN } \\
\cline { 2 - 4 } & $\mathbf{( 1 - 1 0 )}$ & $\mathbf{( 1 - 1 0 )}$ & $\mathbf{( 1 - 1 0 )}$ & \\
\hline Over-Current & 9 & 10 & 5 & 450 \\
\hline Low Resistance & 8 & 3 & 1 & 24 \\
\hline Over heating & 6 & 1 & 9 & 54 \\
\hline Dirt & 9 & 4 & 5 & 180 \\
\hline Moisture & 6 & 5 & 1 & 30 \\
\hline Vibration & 10 & 10 & 4 & 400 \\
\hline
\end{tabular}

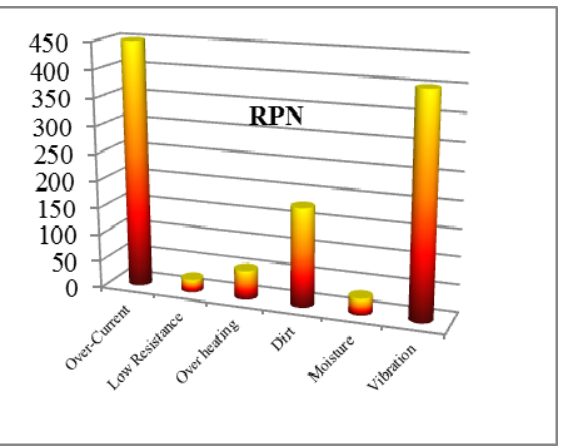

Fig. 6. RPN motor failures distribution

\section{CONCLUSION}

In this study the researchers designed a potential FMECA framework for the CIM conveyor belt as an analytical technique utilized primarily to ensure that the mechanisms of potential failure modes and their associated causes and effects have been considered and addressed. The researchers demonstrated that FMECA is sufficient to derive a reliable conveyor belt safely failure mode system by reducing the risk of failures. They proposed a FMECA framework to facilitate the ability to build and a plan for a preventive maintenance and corrective action. This increased the belt's efficiency and reliability. The study developed a list of potential failure modes and ranked them according to their effect on the conveyor belt.

\section{ACKNOWLEDGMENT}

This research is supported by the deanship of academic research at University of Hail by a grant for project number (0150191).

\section{REFERENCES}

[1] R. K. Mobley, Maintenance Engineering Handbook, McGraw-Hill Professional, 2001

[2] NASA, Apollo gray team lunar landing design final report, 2007

[3] Reliability Analysis Center, Failure mode effects and criticality analysis (FMECA), Reliability Analysis Center, Rome, NY, 1993

[4] MIL-STD-1929A, Procedure for performing a failure mode effects and criticality analysis (FMECA), Washington, DC, 1980

[5] SAE International, J1739, Potential failure mode and effects analysis in design (Design FMEA), potential failure mode and effects analysis in manufacturing and assembly processes (Process FMEA), SAE International, 2009

[6] U.S. Department of Defence, MIL-HDBK-217F, Reliability prediction of electronic equipment, 1991

[7] Naval Surface Warfare Center, Handbook of reliability prediction procedures for mechanical equipment, Naval Surface Warfare Center, Carderock Division, W. Bethesda, Maryland, 2011

[8] I. Y. Tumer, R. B. Stone, "Mapping Function to Failure Mode During Component Development"; Research in Engineering Design, Vol. 14, No. 1, pp. 25-33, 2003

[9] N. S. Arunraj, J. Maiti, "Risk-based maintenance Techniques and applications", Journal of Hazardous Materials, Vol. 142, No. 3, pp. 653661, 2007

[10] H Arabian-Hoseynabadi, H. Oraee, P. J. Tavner "Failure Modes and Effects Analysis (FMEA) for wind turbines", International Journal of Electrical Power \& Energy Systems, Vol. 32, No. 7, pp. 817-824, 2010

[11] H. C. Liu, L. Liu, N. Liu, "Risk evaluation approaches in failure mode and effects analysis: A literature review", Expert Systems with Applications, Vol. 40, No. 2, pp. 828-838, 2013

[12] T. M. El-Dogdog, A. M. El-Assal, I. H. Abdel-Aziz, A. A. El-Betar, "Implementation of FMECA and Fishbone Techniques in Reliability Centered Maintenance Planning", International Journal of Innovative Research in Science, Engineering and Technology, Vol. 5, No. 11, pp. 18801-18811, 2016

[13] T. S. Parsana, M. T. Patel, "A Case Study: A Process FMEA Tool to Enhance Quality and Efficiency of Manufacturing Industry", International Journal of Industrial Engineering and Management Science, Vol. 4, No. 3, pp. 145-152, 2014 